\title{
ALGUNAS CONSIDERACIONES ACERCA DE LA LEY APLICABLE EN LA SUPERACIÓN DEL PASADO DE LA REPÚBLICA DEMOCRÁTICA ALEMANA
}

\author{
SOME CONSIDERATIONS ABOUT THE APPLICABLE LAW IN THE OVERCOMING OF THE PAST OF \\ THE GERMAN DEMOCRATIC REPUBLIC
}

Andrés Falcone

\begin{abstract}
Resumo:
Neste artigo o autor analisa os caminhos da justiça de transição na antiga Alemanha oriental, a partir de uma apreciação doutrinária das teorias negativa (Günther Jakobs) e positivas (Klaus Lüderssen e Ulfrid Neumann).

Palavras-chave: Justiça de Transição. Antiga Alemanha oriental. Superação do passado.
\end{abstract}

\begin{abstract}
:
In this paper the author analyses the ways of transitional justice in the old East Germany, with a doctrinarian appreciation of the negative (Günther Jakobs) and positive theories (Klaus Lüderssen and Ulfrid Neumann).
\end{abstract}

Keywords: Transitional Justice. Former East Germany. Overcoming the past.

1. Introducción

Finalidad de este trabajo es recorrer el arduo sendero que debió atravesar la República Federal de Alemania luego de la anexión ${ }^{1}$ de la ex República Democrática Alemana $^{2}$ en lo atiente a la superación del pasado de este Estado a través del Derecho Penal. ${ }^{3}$

El autor es abogado egresado de la Universidad Nacional de Mar del Plata (Argentina), Magíster Legum LL. M. (Universität Regensburg- Alemania) y doctorando en la misma universidad, bajo la orientación del Prof. Dr. Dres. h. c. Friedrich-Christian Schroeder.

1 Ha sido discutida la naturaleza de la formación de la nueva República Federal de Alemania. Se han referido a ella como "unificación", "reunificación", "adhesión", etc. Aunque entendemos que extendernos en este punto significaría desviarnos de nuestro objeto y preferimos cederle su estudio a la historia y a la Teoría del Estado, coincidiremos con Lüderssen en que el concepto "adhesión" (Beitritt) resulta el más apropiado. LC̈DERSSEN, Klaus. Zu den Folgen des „Beitritts“ für die Strafjustiz der Bundesrepublik Deutschland. Strafverteidiger, Colónia, p. 482-487, 1991. p. 482-483.

2 En adelante nos referiremos a este extinguido Estado como DDR, en función de sus iniciales en idioma alemán Deutsche Demokratische Republik.

3 Coincidiremos con Schroeder en que en la superación del pasado dictatorial no puede encontrarse el Derecho Penal en soledad, sino que paralelamente se requiere una elaboración cultural conjunta (parallele gesellschaftlich-kulturelle Aufarbeitung), la cual debe ser impulsada principalmente por el Estado. SCHROEDER, Friedrich-Christian. Möglichkeiten und Formen der Bewältigung staatskrimineller Vergangenheit. In: RLL, Bernd. Vergangenheitsbewältigung im Osten: Russland, Polen, Rumänien. München: Hanns-Seidel-Stiftung, 2008. p. 9-16. p. 9-10;14-16. Distinta es la posición de Pastor quien 
La importancia del estudio de esta segunda experiencia alemana no se reduce meramente a su comprensión, sino que de la misma pueden inferirse soluciones de posible aplicación en la justicia de transición en distintas partes del globo. ${ }^{4}$ Esto resulta especialmente relevante en relación con el nuevo impulso que ha tomado la justicia intertemporal en Argentina luego de la declaración de imprescriptibilidad de los crímenes de lesa humanidad (caso Arancibia $\mathrm{Clavel}^{5}$ ) y de la inconstitucionalidad de las leyes de Obediencia debida y Punto final (caso Simón ${ }^{6}$ ) por parte de la Corte Suprema de Justicia de la Nación. Pero antes de introducirnos en las discusiones dogmáticas que el tema ha suscitado en la doctrina alemana es menester referirnos a las algo más de cuatro décadas de existencia de la DDR y a su inclusión en la Alemania Federal.

\section{Breve referencia histórica a la Deutsche Demokratische Republik}

Luego de la desaparición del tercer Reich tras la derrota del nacionalsocialismo en la segunda guerra mundial el territorio alemán se encontraba devastado y sus habitantes empobrecidos. Las cuatro fuerzas vencedoras se dividieron el territorio formando las zonas de ocupación francesa, norteamericana, inglesa y soviética. Los comandantes supremos de las fuerzas armadas de las cuatro potencias formaron un Consejo de Control Aliado con sede en Berlín, la capital. En junio de 1945 se formó la Administración Militar Soviética en Alemania, cuyo jefe supremo fue el mariscal G. Zhukov. ${ }^{7}$

sostiene la preponderancia de la reconciliación de la comunidad, a partir de un análisis sociológico, y el descubrimiento de la verdad histórica por sobre la persecución penal del agente, PASTOR, Daniel. “¿Procesos penales sólo para conocer la verdad? La experiencia argentina". In: PASTOR, Daniel. Neopunitivismo y neoinqusición. Buenos Aires: Ad hoc, 2008. p. 369-428. p. 428.

Sobre la relación género-especie entre la superación de la historia (Geschichtsbewältigung) y la superación del pasado (Vergangenheitsbewältigung), Geschichtsbewältigung durch Strafrecht? In: HOYER, Andreas. Beiträge zur gesetzgebungslehre und zur strafrechts dogmatik. Heidelberg: Müller, 2001. p. 62-84. p. 62.

4 Los procesos judiciales de superación de dictaduras pasadas por los nuevos Estados democráticos presentan, salvando las singularidades de cada caso, denominadores comunes, lo que vuelve especialmente útil el empleo del método comparativo. Entre estos denominadores comunes se destacan los problemas vinculados al principio de legalidad, como son el respeto a la garantía de irretroactividad de la ley penal y la prescripción de la acción penal. Otros obstáculos para la punición suelen ser los problemas vinculados a la autoría mediata, a las amnistías dictadas, a las absoluciones en procesos fictos en relación a principio de non bis in idem y a la avanzada edad de los procesados. Cfr. SCHROEDER, Friedrich-Christian. Möglichkeiten und Formen der Bewältigung staatskrimineller Vergangenheit. In: RILL, Bernd. Vergangenheitsbewältigung im Osten: Russland, Polen, Rumänien. München: Hanns-Seidel-Stiftung, 2008. p. 9-16. p. 10-11. Un somero análisis de las circunstancias socio-políticas que rodean la asunción, el desarrollo y la transición democrática de los estados dictatoriales en MUÑOZ CONDE, Francisco. Relación de síntesis. In: SEMINARIO HUMBOLDTKOLLEG, 2008, Sevilla. La transformación juridica de las dictaduras en democracias y la elaboración jurídica del pasado. Sevilla: Universidad Pablo de Olavide. Disponível em: <http://www.cienciaspenales. net>. Acesso em: 11 dez. 2009. p. 2.

5 Fallos: 327:3312.

6 Fallos: 328:2056.

7 Cfr. MÄHLERT, Ulrich. Kleine Geschichte der DDR. München: Verlag C.H. Beck, 2007.p. 18 ss. También WEBER, Hermann. Die DDR: 1945-1990. Munich: Oldenbourg Wissenschaftsverlag, 1999. p. 3 ss. 
Con origen en aquella administración militar se funda el siete de octubre de 1949 la República Democrática Alemana, con un sistema político-económico marxistaleninista y con la Unión de las Repúblicas Socialistas Soviéticas como su aliado de mayor jerarquía. Su territorio se conformaba por el sector oriental del actual territorio alemán más la zona oriental de Berlín, ciudad que sufrió la división en dos por el histórico muro. Su población superaba hacia 1990 los dieciséis millones de habitantes. La conducción del Estado estaba a cargo del SED (Sozialistische Einheitspartei Deutschlands) dirigido sucesivamente por Walter Ulbricht (1950-1971), Erich Honecker (1971-1989) y Egon Krenz (1989). ${ }^{8}$

En el marco de la guerra fría la DDR se alineo detrás de la URSS y reprodujo su modelo económico-político, lo que trajo aparejado un avance desmedido del Estado sobre la esfera privada de los ciudadanos. En este escenario trasciende la Stasi (Ministerium für Staatssichercheit), órgano de inteligencia del Estado que centraba sus operaciones en Berlín oriental. El antiliberalismo político sumado a la austeridad económica y la inminente caída del sistema comunista de la Unión Soviética posibilitó la reunificación del pueblo alemán con la caída del muro divisorio el nueve de noviembre de 1989. La disolución del Estado y la adhesión se oficializaron el tres de octubre de $1990{ }^{9}$

3. Los procesos judiciales en el marco de la adhesión

Aún antes de la adhesión comenzaron los procesos contra los crímenes de la DDR. El veinticuatro de noviembre de 1989 se condenó a un policía (Volkspolizist) a la pena de catorce meses de prisión por su accionar en la represión contra manifestantes en la protesta contra los festejos oficiales por los cuarenta años de existencia de la DDR. Afirma Schroeder que estos procesos estaban todavía ceñidos por las características distintivas de la justicia de la DDR: una reacción ligera y la imposición de duras penas con la principal finalidad de acallar rápidamente el reclamo popular. Desde el treinta de noviembre hasta el cinco de diciembre de 1989 comenzaron numerosas investigaciones por desfalco (Untreue) contra miembros de la cúpula del SED. El ocho de agosto de 1990 se procesó al ex secretario general del partido Erich Honecker por desfalco, abuso de confianza (Vertrauensmissbrauch) y sospecha por su participación en homicidios y lesiones en la "protección de la frontera" Simultáneamente, en marzo de 1990, 73 personas fueron procesadas por fraude electoral (Wahlfälschung) y meses después el procurador general

8 Cfr. WEBER, Hermann. Die DDR: 1945-1990. Munich: Oldenbourg Wissenschaftsverlag, 1999. p. 28-55. También FÜLBERTH, Georg. Finis Germaniae: deutsche geschichte seit 1945. Köln: Verlagsges Papyrossa, 2007. p. 31 ss. Véase un didáctico estudio cronológico en BENZ, Wolfgang. Deutschland seit 1945: Entwicklungen in der Bundesrepublik und in der DDR. München: Moos und Partner, 1990.

9 Cfr. FÜLBERTH, Georg. Finis Germaniae: deutsche geschichte seit 1945. Köln: Verlagsges Papyrossa, 2007. p. 61 ss. 
de la DDR Wendland, su representante Borchert y el procurador general de Berlín Simon fueron procesados por prevaricato (Rechtsbeugung). ${ }^{10}$

En Berlín hacia 1990 se creó una división auxiliar de la fiscalía general abocada especialmente a "crímenes de gobierno" (Arbeitsgruppe Regierungskriminalität) de toda la DDR. El establecimiento de estos organismos especiales resultó fundamental para el descongestionamiento de las fiscalías ordinarias. Este grupo de trabajo que colaboraba en 260 casos hacía 1990 lo hacía en 7314 para 1998. Paralelamente se creó otra división dependiente de la fiscalía generar de Berlín (Dezernat) encargada de contribuir con lo allí sucedido. La misma, que se abocaba a 122 casos en 1990, lo hacía en 3330 en $1993 .{ }^{11}$

Entre el gran número de procesamientos, algunos comenzados durante la existencia de la DDR y continuados en la nueva República Federal, se destacaron los siguientes ilícitos: fraude electoral, espionaje, prevaricato y los homicidios y lesiones producto del cruce de fronteras a través del muro de Berlín. ${ }^{12}$ Este último caso es el que, por la importancia de los bienes jurídicos lesionados y por el significado político que significa el ultraje al derecho político de emigrar, más ha preocupado a los científicos del Derecho Penal y consecuentemente más atención le dedicaremos.

4. La superación del pasado de la DDR en la doctrina alemana

La justicia de transición suele presentar los inconvenientes generales mencionados ut supra, sin embargo los límites del presente estudio nos impiden abocarnos a todos ellos, por lo que nos dedicaremos a desentrañar cual es la ley que ha de aplicarse a la punición de los homicidios en el muro y en que medida debe ser esta reconocida por los tribunales de la República Federal. ${ }^{13}$

10 Cfr. sobre todo SCHROEDER, Friedrich-Christian. Zehn Jahre strafrechtliche Aufarbeitung des DDRUnrechts. Neue Juristische Wochenschrift, München, n. 41, p. 3.017-3.021, 2000, p. 3.017.

1 Cfr. Id. Ibid., p. 3.018.

12 Cfr. Id. Ibid., p. 3.017-3.018. LÜDERSSEN, Klaus. Zu den Folgen des „Beitritts“ für die Strafjustiz der Bundesrepublik Deutschland. Strafverteidiger, Colónia, p. 482-487, 1991. p. 483-484. Vornbaum, por su parte, sostiene que la "patología especial" (Spezielle Pathologie) de la DDR fueron, además de los crímenes fronterizos, las adopciones forzosas, las deportaciones y los denominados Waldheimer Prozesse (procesamientos contra jerarcas nazis sin el mínimo respeto a las reglas del debido proceso). Por otra parte, es interesante el estudio que hace el autor sobre la impunidad que favoreció a los jueces de la DDR a la hora de afrontar los procesos por prevaricato, sosteniendo la existencia de un Richterprivileg similar al existente en la superación del pasado nacionalsocialista. Cfr. VORMBAUM, Thomas. Einführung in die moderne Strafrechtsgeschichte. Heidelberg: Spring, 2009. p. 257-259.

13 De esta forma se prescinde aqui del análisis de la superación de las leyes de amnistía dictadas a favor de los criminales de la DDR y de la de la prescripción de ciertos delitos por parte de las instituciones de la República Federal de Alemania. Sólo se sostendrá sucintamente en relación al primer tópico que el BGH (Bundesgerichtshof- Tribunal Supremo Federal) decidió que tras una reinterpretación (más restringida) de los presupuestos fácticos de las leyes de amnistía los casos investigados no se encontraban por ellas 
Seguidamente se expondrán los exámenes de los juristas que a nuestro entender se han referido a la problemática de forma más aventajada. Sus soluciones, aunque como se observará presentan matices distintos, pueden ser clasificadas en dos concurridos conjuntos: aquellos cuya solución es positiva, es decir, se pronuncian en favor de la punición de los criminales de la DDR y aquellos cuya conclusión es negativa. Comenzaremos con estas últimas.

\section{a. Las tesis negativas}

El penalista y filósofo del Derecho Günther Jakobs sostiene que en caso de fractura política (transición democrática) son tres las condiciones que han de darse para la imposición de una pena, por los hechos acaecidos durante el régimen anterior: imputabilidad, necesidad y positividad. Con respecto a la imputabilidad, ha de evaluarse si es en realidad la "mala voluntad del agente" la causa fundamental del mal acaecido o si en realidad ella es una causa menor, irrelevante, en comparación con las verdaderas, estructurales, que llevaron al sujeto a colocarse en esa situación. El ejemplo proporcionado es el siguiente: si en un Estado se les enseñara a los niños en edad escolar a delinquir, entonces el verdadero origen de los crímenes cometidos no sería la mala voluntad de los autores sino las falencias del sistema educativo. ${ }^{14}$

amparados. Por otra parte, difícilmente pueda amnistiase un crimen cuya persecución siempre estuvo fuera del alcance de la justicia. Véase al respecto BGH, NJW 1994, p. 3239. Por otro lado, y con respecto a la prescripción se sancionó una ley el veintitrés de marzo de 1993 en donde se establecía que todos los crímenes que por motivos políticos o por causas contrarias al Estado de Derecho no hayan podido ser juzgados no han de prescribir. Incluso aquellas conductas que fueran delitos según la normativa de la República Federal. Véase la confirmación del BGH en BGHSt 40, p. 55. Con posterioridad se dictaron tres leyes más donde se estableció que la prescripción de dichos crímenes no podia acaecer antes del dos de octubre de 2000 (diez años después de la adhesión). Más extenso en SCHROEDER, Friedrich-Christian. Zehn Jahre strafrechtliche Aufarbeitung des DDR-Unrechts. Neue Juristische Wochenschrift, München, n. 41, p. 3.017-3.021, 2000.

14 JAKOBS, Günther. Vergangenheitsbewältigung durch Strafrecht?- Zur Leistungsfähigkeit des Strafrechts nach einem politischen Umbruchn. In: ISENSEE, Josef. Vergangenheitsbewältigung durch Recht: drei abhandlungen zu einem deutschen problem. Berlin: Duncker \& Humblot, 1992. p. 137-158. p. 38. Esto es, según nuestro entender, una verdad a medias, ya que tanto en situaciones de fractura constitucional como de vigencia de la misma las circunstancias que llevan al agente a cometer el ilícito penal sueten estar vinculadas con falencias del sistema sociopolítico y sin embargo en situaciones "normales" esto no es tenido en cuenta para la completa desincriminación. Prima facie no sería la "mala voluntad del agente" la que llevaría a un niño en estado de riesgo habitante de una villa de emergencia del conourbano bonaerense a asaltar una verduleria, sino que posiblemente sean graves deficiencias del sistema sociopolítico argentino (desocupación, marginalidad, pobreza, etc.) las que han gravitado para llevarlo a la comisión del hecho. Sin embargo, y a pesar de que esto salta a la vista, la extrema situación del menor, sería en el mejor de los casos tenida en cuenta sólo para atenuar su culpabilidad. El interrogante que se infiere de este análisis es el siguiente: ¿por qué han de gozar antiguos dictadores de consideraciones omitidas para agentes comunes en situación de riesgo? 
Con miras a la necesidad, Jakobs considera que la pena ha de servir para el reestablecimiento de la vigencia de la norma lesionada, de tal manera que si por otros medios la misma permanece incólume, la pena no tendría rezón de ser. Así en una sociedad donde el totalitarismo esté completamente fuera de discusión, frente a intentos totalitarios residuales, bastará con "encogerse de hombros y mirar sin entender" 15

La positivización se entiende como el hecho punible por el ordenamiento jurídico "de aquí y ahora" Respetándose así el principio de territorialidad de la ley penal ( $33 \mathrm{StGB}$ ) y la prohibición de retroactividad (art. 103, $2 \mathrm{GG} ; \S 1 \mathrm{StGB}$ ). ${ }^{16}$ Igualmente el Derecho Penal alemán reconoce su vigencia para hechos cometidos en el extranjero por un alemán (principio de personalidad activo) o contra un alemán (principio de protección), "cuando el hecho esté amenazado con una pena en el lugar de su comisión, o el lugar de los hechos no este sujeto a jurisdicción penal alguna" ( $\$ 7 \mathrm{StGB}) .{ }^{17}$

Seguidamente analiza Jakobs el caso de la DDR y pone a prueba los tres criterios establecidos. Lo primero que evalúa el autor es la ley aplicable a los delitos cometidos en la DDR. Siendo que el Derecho Penal alemán se aplica a los hechos

15 JAKOBS, Günther. Vergangenheitsbewältigung durch Strafrecht?- Zur Leistungsfähigkeit des Strafrechts nach einem politischen Umbruchn. In: ISENSEE, Josef. Vergangenheitsbewältigung durch Recht: drei abhandlungen zu einem deutschen problem. Berlin: Duncker \& Humblot, 1992. p. 137-158. p. 38. La crítica aquí es de otra naturaleza y esta vinculada a que en realidad no existe en el mundo actual, según nuestro entender, ningún Estado en donde "un giro al totalitarismo esté completamente fuera de discusión" Lamentablemente debido, entre otras causas, a dirigentes políticos oportunistas y a medios de comunicación, tendientes a provocar una permanente sensación de inseguridad en sociedad, que consecuentemente le exigirá al Estado se convierta en un mero ente ejecutor de la venganza pública. Debido a esto es que el totalitarismo nunca esta fuera de discusión. Asiste razón a Schroeder al sostener que por defender posturas similares es que luego del nacionalsocialismo Alemania debió atravesar un segundo gobierno autoritario. SCHROEDER, Friedrich-Christian. Zur Strafbarkeit von Tötungen in Staatlichem Auftrag. Juristenzeitung, Tübingen, p. 990-993, 1992. p. 992. Además Schroeder ha criticado con dureza este requisito de necesidad de pena ya que esto le otorgaría al juez una discrecionalidad incompatible con el Estado de Derecho y el principio de legalidad. Solo en contadas excepciones puede el juez apartarse de la ley y dejar de aplicar la pena, ya que esta evaluación sobre la necesaridad o innecesaridad le corresponde al legislador a la hora de crear el tipo penal o de amnistiar. Idem, p. 990.

16 GG son las siglas de Grundgesetz, Ley Fundamental alemana y StGB de Strafrechtgesetzbuch, Código Penal alemán. Así nos referiremos a estos textos a lo largo del presente trabajo. La vigencia del principio de prohibición de retroactividad en casos de fractura constitucional ha sido ampliamente discutido en doctrina. Dencker sostiene que una abierta ruptura del mismo es posible, y que este de ningún modo es aplicable al caso de la DDR. Similar NAUCKE, Wolfgang. Die strafjuristische priviliegierung staatsverstarker kriminalität. Frankfurt: V. Klostermann, 1996. p. 47 ss. Schroeder, en igual sentido, afirma que la finalidad de la prohibición de retroactividad es evitar la aplicación de arbitrarias leyes ad hoc volviendo así al Derecho "previsible y calculable"; el Estado de Derecho no es, consecuentemente, un fin en sí mismo. No han sido la falta de previsibilidad ni de calculabilidad lo que llevó a que se cometieran los ilícitos en estudio. SCHROEDER, Friedrich-Christian. Zehn Jahre strafrechtliche Aufarbeitung des DDR-Unrechts. Neue Juristische Wochenschrift, München, n. 41, p. 3.017-3.021, 2000. p. 3.019; SCHROEDER, FriedrichChristian. Zur Strafbarkeit von Tötungen in Staatlichem Auftrag. Juristenzeitung, Tübingen, p. 990-993, 1992. p. 992. En similar posición también Alexy, cuyas reflexiones serán tratadas ut infra.

17 JAKOBS, Günther. Vergangenheitsbewältigung durch Strafrecht? Zur Leistungsfähigkeit des Strafrechts nach einem politischen Umbruchn. In: ISENSEE, Josef. Vergangenheitsbewältigung durch Recht: drei abhandlungen zu einem deutschen problem. Berlin: Duncker \& Humblot, 1992. p. 137-158. p. 38. 
cometidos en el "interior del territorio" ( $\$ 3 \mathrm{StGB}$ ) ha de evaluarse si la ex DDR no fue también parte de este, y en todo caso la no ejecución del sistema de sanciones penales se correspondería con un problema de ejecución penal, ajeno a la cuestión en tratamiento y solucionado luego de la reunificación. Sin embargo luego del Pacto de Varsovia de 1970 y del Tratado Fundamental de 1972 la jurisprudencia ${ }^{18}$ y la doctrina entendieron como interior del territorio a la República Federal y a Berlín occidental. Por ello dejó de lado el $\S 3$ StGB y se comenzó a evaluar la competencia a partir de los principios de personalidad activo y de protección ( $\$ 7 \mathrm{StGB}$ ), a través de ellos podría llegarse a la punición. Pero el Derecho Penal alemán se relativiza a si mismo y consecuentemente es aplicable este principio sólo cuando el hecho sea sometido a pena en el lugar de comisión (asegurándose así la existencia de un ordenamiento jurídico similar al propio) o en casos en donde el lugar de comisión no reconozca jurisdicción penal. ${ }^{19}$ Siendo que defender esta segunda solución resultaría mucho más complejo, ${ }^{20}$ Jakobs se empeña en demostrar que los delitos cometidos no eran tales según el ordenamiento jurídico de la DDR, con lo que se desplomarían simultáneamente la aplicación del Derecho de la República Federal para entender en el caso y el tercer criterio: la positividad.

Deteniéndonos en los homicidios en la frontera, eje central de nuestro estudio, la normativa en la DDR era la siguiente: hasta la entrada en vigor de la Ley de Fronteras (DDR- GrenzG) en 1982 rigió la Ley sobre funciones y competencias de la policía popular alemana (VoPoG) de 1968. Según esta los miembros del ejército popular debían "ejecutar las competencias reguladas en esta ley [...] de conformidad con las instrucciones del Ministerio para la Defensa Nacional" Paralelamente a la VoPoG existía una Orden del Ministerio del Interior y Jefe de la Policía Popular alemana

18 Cfr. BGHSt, 30, p. 1 ss.

19 Más extenso, aprobando esta solución del legislador JAKOBS, Günther. Untaten des Staates: unrecht im StaatUnrecht im Staat. Strafe für die Tötungen an der Grenze der ehemaligen DDR? Goltdammer's Archiv für Strafrecht, p. 1-19, 1994. p. 4.

20 Hruschka es de la opinión de que en la disonancia entre el Derecho formal de la DDR (relativamente respetuoso de los $\mathrm{DDHH}$ ) y el Derecho material, mediante el cual se producian graves atropellos arrojaba como resultado un vacío normativo, ya el Derecho vigente no era finalmente ni el formal ni el material. Esto habilitaba consecuentemente el $\S 7 \mathrm{StGB}$, que permitía a su vez la aplicación del Derecho de la República Federal. Cfr. HRUSCHKA, Joachim. Die Todesschüsse an der Berliner Mauer vor Gericht. Juristenzeitung, v. 47, n. 13 , p. $665-670,1992$. p. 669 ss. Contrariamente Jakobs afirma que en realidad un lugar no sometido a jurisdicción penal alguna sería aquel en que cualquier Estado podria intervenir validamente sin interferir en asuntos de otro Estado. Para Jakobs una solución como la de Hruschka no sería aceptable ya que cualquier Estado intervendría en otro cuando considere que este no esta respetando los DDHH, y siendo que las naciones tienen ideas distintas sobre lo que es o no correcto, esta solución no tiene razón de ser. Günter Jakobs, Untaten des Staates- Unrecht im Staat - Strafe für die Tótungen an der Grenze der ehemmaligen DDR?, en: GA 1994, pp. 10-11. Coincidiendo con Jakobs y oponiéndose a que la DDR, como territorio no sujeto a potestad punitiva alguna, reciba un tratamiento similar a la Antártida SCHROEDER, FriedrichChristian. Zur Strafbarkeit von Tötungen in Staatlichem Auftrag. Juristenzeitung, Tübingen, p. 990-993, 1992. p. 991. 
de junio de 1972 que establecía que las armas de fuego sólo serán empleadas por los custodios de la frontera de conformidad con las instrucciones militares del ministerio de defensa. Lamentablemente instrucciones de esta naturaleza hubo suficientes. Antes de la VoPoG sólo existían disposiciones internas de servicio en forma de órdenes del ministro competente. La formulación tanto del §27.2.1 GrenzG como del § 17.2.a VoPoG, que coincidían casi literalmente, permitía abrir fuego para evitar la comisión o la continuación de un delito (el delito en cuestión era el cruce ilegal de fronteras \$213 StGB-DDR, con la mayor protección posible a la vida, incluso prestando primeros auxilios al sujeto herido y evitando disparar a niños y mujeres $(\S 27.4-5 \mathrm{GrenzG}),{ }^{21}$ algo que en la práctica no ocurrió.

A pesar de esto Jakobs considera que estos hechos no eran punibles según el Derecho de la DDR. Según él, entender el Derecho de la DDR como aparecía "en el papel" (Ley de Fronteras, etc.) es desacertado ya que en la práctica, en este caso, se empleó cualquier medio para evitar el cruce ilegal de fronteras, incluso disparar una ráfaga de ametralladora sobre un indefenso, sin ser el ejecutante pasible de ninguna sanción. La norma, entonces, no era la norma escrita y publicada sino una reglamentación real fundamentada en la "construcción jerárquica del Estado absolutista" "una práctica generalizada al margen del Derecho" 22

En relación al segundo requisito, la necesidad, es rechazada por Jakobs al sostener que tras la reunificación no existen posibilidades de que sucedan casos comparables en situaciones comparables, de forma tal que la norma no necesita reafirmar su vigencia a través de la pena. ${ }^{23}$

La imputabilidad como criterio de punición tampoco mereció un extenso desarrollo. Se la niega distinguiendo entre los soldados fronterizos y los encargados de la conducción del Estado. Los primeros no han sido para Jakobs la causa de la producción de los ilícitos sino la perversión del sistema. Los segundos tampoco son punibles ya que no

21 El presupuesto normativo de la causal de justificación contenida en $\$ 27$ GrenzG y en $\S 17$ VoPoG permitía una interpretación restrictiva conforme a los principios del Estado de Derecho. No se podia disparar a cualquier fugitivo bajo cualquier circunstancia, sino que se debían tomar las precauciones necesarias para, intentar evitar pérdidas humanas y lesiones graves. A su vez estos preceptos legales han de combinarse con el art. 12 del Pacto Internacional sobre Derechos Civiles y Políticos, suscripto por la DDR, donde se garantizaba el derecho a abandonar el propio Estado y el § 95 StGB-DDR donde se establecía que la desatención a derechos humanos o fundamentales no podía ampararse en ninguna ley. Véase al respecto SCHROEDER, Friedrich-Christian. Zur Strafbarkeit von Tötungen in Staatlichem Auftrag. Juristenzeitung, Tübingen, p. 990-993, 1992. p. 991. Sobre el tema volveremos ut Infra.

22 Cfr. JAKOBS, Günther. Untaten des Staates: unrecht im StaatUnrecht im Staat. Strafe für die Tötungen an der Grenze der ehemaligen DDR? Goltdammer's Archiv für Strafrecht, p. 1-19, 1994. p. 6-7. También JAKOBS, Günther. Vergangenheitsbewältigung durch Strafrecht? Zur Leistungsfähigkeit des Strafrechts nach einem politischen Umbruchn. In: ISENSEE, Josef. Vergangenheitsbewältigung durch Recht: drei abhandlungen zu einem deutschen problem. Berlin: Duncker \& Humblot, 1992. p. 137-158. p. 51.

23 JAKOBS, Günther. Vergangenheitsbewältigung durch Strafrecht? Zur Leistungsfähigkeit des Strafrechts nach einem politischen Umbruchn. In: ISENSEE, Josef. Vergangenheirsbewältigung durch Recht: drei abhandlungen zu einem deutschen problem. Berlin: Duncker \& Humblot, 1992. p. 137-158. p. 51. 
es función del Derecho Penal exportar la concepción de un Estado, sino respetar la de la DDR en este caso. Y allí este sistema político (comunista- autoritario) fue pensado como una fuerza política (no fuerza criminal) capaz de recrear la esperanza de los hombres. ${ }^{2+}$

En sentido similar Pawlik sostiene que es imposible justificar la punición a partir del Derecho de la DDR, ya que en realidad este estaba fuertemente condicionado por la política, de tal modo que ambos eran inescindibles. El apego al derecho natural para la corrección del positivo significaría no otra cosa que la translación hacia la política de cuestiones ajenas ella, dejando entrever el fuerte contenido ideológico de los procesamientos..$^{25}$

b. Las tesis positivas

El Tribunal Territorial de Berlín, junto con la doctrina mayoritaria, prescindió del análisis del $\S 7$ y se abocó al art. 315 de la Ley de Introducción al Código Penal (Einführungsgesetz zum Strafgesetzbuch), recogido en el Anexo I del Tratado de Unificación (Einigungsvertrag). Este art. titulado "Validez del Derecho Penal para los hechos acaecidos en la DDR" (Geltung des Strafrechts für in der Deutschen Demokratischen Republik begangene Taten) establece en su inciso primero, de conformidad con el $\$ 2$ StGB que los acontecimientos producidos en la DDR no podrán ser imputados a sus autores si según en ordenamiento jurídico allí vigente los mismos no eran pasibles de sanción. El inciso cuarto del art. 315 establece, en lo pertinente, que el inciso primero sólo tendrá aplicación siempre y cuando para el hecho no hubiera sido aplicable el Derecho de la República Federal aún antes de la adhesión. El tribunal territorial interpreto que en todo caso por imperio del principio de la aplicación de la ley penal más benigna ( $\$ 2.3 \mathrm{StGB}$ ) ha de aplicarse el Derecho de la DDR frente al de la República Federal. Así se analizó la normativa para la custodia de la frontera como una supuesta causal de justificación, negando finalmente su existencia al interpretar los preceptos legales de conformidad con los principios del Estado de Derecho. ${ }^{26}$

Esto llevó al BGH, órgano revisor, a confirmar el resultado de la sentencia en primera instancia, aunque no su fundamentación. Se opuso a que dichos sucesos fueran

\footnotetext{
24 Id. Ibid., p. 51. Posiciones similares a la de Jakobs en GRÜNWALD, Gerald. Die strafrechtliche Bewertung in der DDR begangener Handlungen. Strafverteidiger, Colónia, p 31-37, 1991. p. 33 ss y ROELLECKE, Gerd. Schwierichkeiten mit der Rechtseinheit nach der Deutschen Wiedervereinigung. Neue Juristische Wochenschrift, München, p. 650, 1991. p. 659 ss.

25 Cfr. PAWLIK, Michael. Strafrecht und Staatsunrecht: zur strafbarkeit der mauerschützen. Goltdammer's Archiv für Strafrecht, p. 472- 483, 1994. p. 472 ss. Crít. NEUMANN, Ulfrid. Rechtspositivismus, rechtsrealismus in der diskussion um die strafrechtliche bewältigung politischer systemwechsel. In: PRITTWITZ, Cornelius et al. Festschrift für Klaus Lüderssen. Baden-Baden: Nomos, 2002. p. 109- 126. p. 123, 126.

26 Cfr. BGHSt 40, p. 248 ss.
} 
punibles a partir del Derecho vigente en la DDR afirmando que el derecho positivo excede el tenor literal de la ley abarcando también la práctica interpretativa. Consecuentemente la normativa de protección de frontera justificaba los homicidios producidos. ${ }^{27}$

Sin embargo, el BGH evalúa estas causales de justificación a la luz de la fórmula de Radbruch, a saber: cuando la contradicción entre la ley positiva y la justicia se torna insoportable, aquel ha de ceder ante $e s t a,{ }^{28}$ y consecuentemente rechaza su aplicación. La astucia, a nuestro juicio, del BGH consiste efectuar una "positivización" de la conocida fórmula, no contrastando la letra de la ley con una "justicia a partir del derecho natural" sino con los compromisos internacionales asumidos por la DDR, destacándose entre ellos la Declaración Universal de los Derechos Humanos de $1948 .{ }^{29}$ El guardia fronterizo no sufriría ningún engaño en su confianza en la norma sino en que se mantendrá una determinada interpretación del derecho escrito, la cual que no puede ser digna de tutela, ya que la misma hade respetarse sólo en relación al derecho escrito (geschriebenes Gesetzesrecht $)^{30}$

Alexy aprueba el rechazo de los fundamentos de la primera instancia apuntando que no puede interpretarse la normativa de la DDR a la luz de los principios del Estado de Derecho de la RFA, so pena de caer en una maniobra interpretativa a posteriori (nachträgliche Uminterpretation), una retroactividad encubierta, más grave aún que la cubierta. Empero, afirma que la solución del BGH cae en el mismo error ya que un inconveniente similar se suscita al oponer la ley escrita al sistema internacional de los Derechos Humanos. Por ello es que, en su opinión, la solución correcta sería considerar como si el art. 103.2 de la Ley Fundamental (prohibición de retroactividad) tuviera una cláusula limitativa no escrita que excluiría la protección de una causal de justificación de esta naturaleza. El resultado sería el mismo que el de la primera instancia y del BGH, pero se estaría exponiendo con claridad "el precio que debe pagarse por ello" ${ }_{31}$

Ulfrid Neumann, parte de la base de que solamente si los disparos en el muro eran punibles según el Derecho de la DDR podrán sus autores ser pasibles de sanción en la República Federal. Para ello el autor propone relacionar los textos legales, la praxis de los tribunales y la calidad moral de las normas en cuestión, para lograr desentrañar que es en realidad el "Derecho" ${ }^{32}$ Estas fuentes, de escasa y en todo caso corregible disonancia

27 BGHSt 40, p. 243 ss.

28 Cfr. RADBRUCH, Gustav. Gesetzliches Unrecht und übergesetzliches Recht. Juristische Zeitgeschichte, Baden-Baden, n. 4, 1946. p. 105 ss.

29 BGHSt 40, p. 244.

30 BGHSt 41, p. 111.

31 Cfr. Alexy, Robert. Derecho injusto, retroactividad y principio de legalidad penal. DOXA: Cuadernos de Filosofia del Derecho, Alicante, n. 23, p. 197-230, 2000. p. 202. Sobre el problema de la retroactividad encubierta en general ALEXY, Robert. Mauerschützen: Zum Verhältnis von Recht, Moral und Strafbarkeit. Göttingen: Vandenhoeck \& Ruprecht, 1993. p. 30

32 NEUMANN, Ulfrid. Rechtspositivismus, rechtsrealismus in der diskussion um die strafrechtliche 
en períodos de normalidad, sufren fuertes contradicciones en Estados de Derecho injusto (Unrechtsstaaten), de allí que es menester establecer un orden jerárquico entre ellas. ${ }^{33} \mathrm{El}$ autor se encarga de desprenderse en primer término del derecho natural, y esto porque a la hora de evaluar ordenamientos jurídicos externos es menester resguardar la inmanencia del sistema. Cuando rechazamos, por ejemplo, la esclavitud en la antigua Grecia amparándonos en fundamentaciones iusnaturalistas, nos basamos en valoraciones "de hoy" distintas a las existentes en aquel sistema. Por supuesto que las posiciones iusnaturalistas dentro del ordenamiento jurídico extranjero o pasado sirve para describirlo, cuestión distinta es si podemos nosotros inferir conclusiones de tales posiciones iusnaturalistas que aquel ordenamiento no extrae. ${ }^{34}$

Oponiendo el realismo al positivismo el autor es concluyente: ¿como puede un realista diferenciar una regla de una infracción colectiva y permanente por parte de los operadores del derecho? Si el derecho positivo hubiera de dejarse de lado en función del derecho judicial ¿llegaríamos a la conclusión de que en puridad en la DDR nunca existió un sistema jurídico legal sino una mera puesta en escena, un simple teatro sostenido por razones de propaganda, al que hoy fuera imposible apelar? Entonces hay que observar la ley de la DDR, con sus garantías "hacia afuera" para evitar que con efectos exculpatorios los imputados aleguen que todo aquello "no iba tan en serio" 35

Las posiciones de Schroeder ${ }^{36}$ y Lüderssen $^{37}$ no presentan grandes disonancias. Basan la posibilidad de aplicación de la pena en la contraposición de dos aristas opuestas del ordenamiento jurídico de la DDR: por un lado las ocultas causales de justificación y por el otro la autorepresentación a partir del $§ 95$ StGB-DDR y los conpromisos internacionales suscriptos. Manteniéndose en el Derecho de la DDR escogen su autorepresentación y se oponen a la justificación de los homicidios en el muro.

Finalmente Küpper - Wilms sostienen que el reconocimiento por parte de la República Federal de las causales de justificación de la DDR, contrarias a los principios del Estado de Derecho, eran violatorias del su orden público (ordre public) y en consecuencia inaceptable. ${ }^{38}$

bewältigung politischer systemwechsel. In: PRITTWITZ, Cornelius et al. Festschrift für Klaus Lüderssen. Baden-Baden: Nomos, 2002. p. 109- 126. p. 112.

33 Id. Ibid., p. 113.

34 Id. Ibid., p. 117.

35 Id. Ibid., p. 124.

36 Cfr. SCHROEDER, Friedrich-Christian. Zur Strafbarkeit von Tötungen in Staatlichem Auftrag. Juristenzeitung, Tübingen, p. 990-993, 1992. p. 991.

37 Cfr. LÜDERSSEN, Klaus. Zu den Folgen des „Beitritts“ für die Strafjustiz der Bundesrepublik Deutschland. Strafverteidiger, Colónia, p. 482- 487, 1991. p 486-487.

38 KÜPPER, Georg; WILMS, Günther. Die Verfolgung von Straftaten des SED-Regimes. Zeitschrift für Rechtspolikit, p. 91-94, 1992. p. 199, 201. 


\section{Toma de postura}

El primer problema que se presenta para la resolución del caso es la ley aplicable. El $\S 7$ StGB de la República Federal no ha sido modificado en los sustancial desde antes del nacimiento de la DDR y según él el Derecho de la República Federal sería aplicable cuando el hecho hubiera sido cometido por o contra un alemán en el extranjero siempre que, como ya analizamos, el territorio no este sujeto a potestad punitiva alguna o "el hecho esté amenazado con una pena en el lugar de su comisión. Por los motivos expuestos en el acápite anterior se rechaza la posibilidad de equiparar jurídicamente la DDR a la Antártida, en palabras de Schroeder. ${ }^{39}$ En la DDR existió un Derecho, conformado por los textos legales y por la práctica judicial, desconocerlo sería un sinsentido. La segunda alternativa, sin embargo, resulta menos lejana.

La decisión del legislador en los principios de personalidad activo y pasivo (este último también denominado principio de protección) es la de tutelar al alemán en el extranjero, aplicando el propio ordenamiento jurídico, respetuoso de los principios del Estado de Derecho, asegurándole así al alemán autor el respeto a las reglas del debido proceso y al alemán víctima el procesamiento de los responsables. Pero como reconoce Jakobs, el Derecho de la República Federal se entiende a sí mismo como relativo y exige "un territorio sin Derecho" o que la conducta este amenazada con una pena. Esto lleva al autor a la confusión de sostener que debido a las causales de justificación estudiadas los homicidios en la frontera no eran punibles según el ordenamiento jurídico de la DDR. Lo que no se advierte es que el legislador de la República Federal no exige un ordenamiento jurídico en el que una pena sea aplicable a esa conducta, sino meramente que esta esté amenazada por aquella. El legislador exige un tipo penal similar al de la RFA en el ordenamiento jurídico extranjero, sin sumergirse en el estudio de sus causales de justificación, justamente para evitar problemas como los que aquí se suscitan. El principio de personalidad, que muchos ordenamientos jurídicos como el argentino desconocen, colabora con la protección del alemán en el extranjero y su incorporación es una decisión eminentemente política, como también los es su alcance. Es el legislador alemán quien decide hasta donde proteger a sus ciudadanos y en este caso la protección alcanza el elevado nivel de tipicidad.

Sin embargo resulta dudosa la aplicación del Derecho de la República Federal en cualquier hecho acaecido en la DDR: un accidente automovilístico, una riña, una estafa, etc.; pero no así el homicidio de un alemán habitante de la DDR que al momento de los hechos huía de allí para ponerse bajo la tutela del ordenamiento jurídico de la RFA, y evitando el de un Estado de policía. Aquí la protección cobra sentido nuevamente.

$39 \quad$ Véase nota 20. 
La doctrina y la jurisprudencia, contrariamente, han preferido recorrer el sendero del art. 315 de la Ley de Introducción al Código Penal. A pesar de ello, el resultado aquí no debiera ser otro, siendo que si bien el inciso primero exige la aplicación del Derecho de la DDR para los actos allí cometidos, el inciso cuarto deja sin efecto a aquel cuando los hechos fueran punibles según el Derecho vigente de la RFA, lo que a nuestro entender acontecía, puesto que los $\$ 212-213$ StGB (homicidio con y sin atenuaciones a la culpabilidad) existen, sin modificaciones en lo sustancial, desde la sanción del código en 1871 .

Aún así la ya estudiada doctrina mayoritaria se inclina por el Derecho de la DDR en función del principio de la ley penal más benigna ( $\$ 2.3 \mathrm{StGB}$ ), para luego, por distintos motivos (fórmula de Radbruch, orden público, interpretación restrictiva conforme a los principios del Estado de Derecho, autorepresentación según el $\$ 95$ StGBDDR y compromisos internacionales, etc.) rechazar o limitar extensamente sus causales de justificación. Por otra parte el StGB- DDR conminaba el homicidio con una pena de no menos de diez años, y hasta 1987 con pena de muerte si el mismo se produjera "contra los Derecho Humanos" mientras que en la República Federal el homicidio esta amenazado con una pena de hasta cinco años y de uno a diez años si se obrare con culpabilidad atenuada.

El interrogante entonces es el siguiente: con este sistema de penas y si a la postre no se han de reconocer las causales de justificación de la DDR ¿cual es la ley penal más benigna? o peor aún ¿si se aplica el Derecho de la DDR sin reconocer las causales de justificación no se estaría en realidad aplicando de forma encubierta el Derecho de la República Federal?

Con una solución como la que estamos defendiendo no sería necesario evaluar la existencia o el reconocimiento por parte de la República Federal de siniestras causales de justificación.

Mar del Plata, febrero de 2011.

\section{Referências}

ALEXY, Robert. Mauerschützen: Zum Verhältnis von Recht, Moral und Strafbarkeit. Göttingen: Vandenhoeck \& Ruprecht, 1993.

Derecho injusto, retroactividad y principio de legalidad penal. DOXA: Cuadernos de Filosofia del Derecho, Alicante, n. 23, p. 197-230, 2000.

BENZ, Wolfgang. Deutschland seit 1945: Entwicklungen in der Bundesrepublik und in der DDR. München: Moos und Partner, 1990. 
FALCONE, Andrés. Superación del pasado alemán a través del Derecho Penal: reflexiones a veinte años de la caída del muro de Berlín. Revista de Derecho Penal, n. 1, p. 389-420, 2010.

FÜLBERTH, Georg. Finis Germaniae: deutsche geschichte seit 1945. Köln: Verlagsges Papyrossa, 2007.

GRÜNWALD, Gerald. Die strafrechtliche Bewertung in der DDR begangener Handlungen. Strafuerteidiger, Colónia, p 31-37, 1991.

HRUSCHKA, Joachim. Die Todesschüsse an der Berliner Mauer vor Gericht. Juristenzeitung, v. 47, n. 13, p. 665-670, 1992.

JAKOBS, Günther. Vergangenheitsbewältigung durch Strafrecht?- Zur Leistungsfähigkeit des Strafrechts nach einem politischen Umbruchn. In: ISENSEE, Josef. Vergangenheitsbewältigung durch Recht: drei abhandlungen zu einem deutschen problem. Berlin: Duncker \& Humblot, 1992. p. 137-158.

. Untaten des Staates: unrecht im StaatUnrecht im Staat. Strafe für die Tötungen an der Grenze der ehemaligen DDR? Goltdammer's Archiv für Strafrecht, p. 1-19, 1994.

KÜPPER, Georg; WILMS, Günther. Die Verfolgung von Straftaten des SED-Regimes. Zeitschrift für Rechtspolikit, p. 91-94, 1992.

LÜDERSSEN, Klaus. Zu den Folgen des „Beitritts“ für die Strafjustiz der Bundesrepublik Deutschland. Strafverteidiger, Colónia, p. 482- 487, 1991.

MÄHLERT, Ulrich. Kleine Geschichte der DDR. München: Verlag C.H. Beck, 2007.

MUÑOZ CONDE, Francisco. Relación de síntesis. In: SEMINARIO HUMBOLDT-KOLLEG, 2008, Sevilla. La transformación juridica de las dictaduras en democracias y la elaboración jurídica del pasado. Sevilla: Universidad Pablo de Olavide. Disponível em: $<\mathrm{http} / / \mathrm{www}$.cienciaspenales. net>. Acesso em: 11 dez. 2009.

NAUCKE, Wolfgang. Die strafjuristische priviliegierung staatsverstarker kriminalität. Frankfurt: V. Klostermann, 1996.

NEUMANN, Ulfrid. Rechtspositivismus, rechtsrealismus in der diskussion um die strafrechtliche bewältigung politischer systemwechsel. In: PRITTWITZ, Cornelius et al. Festschrift für Klaus Lüderssen. Baden-Baden: Nomos, 2002. p. 109- 126.

PASTOR, Daniel. “¿Procesos penales sólo para conocer la verdad? La experiencia argentina”. In: PASTOR, Daniel. Neopunitivismo y neoinqusición. Buenos Aires: Ad hoc, 2008. p. 369- 428.

PAWLIK, Michael. Strafrecht und Staatsunrecht: zur strafbarkeit der mauerschützen. Goltdammer's Archiv für Strafrecht, p. 472- 483, 1994.

ROELLECKE, Gerd. Schwierichkeiten mit der Rechtseinheit nach der Deutschen Wiedervereinigung. Neue Juristische Wochenschrift, München, p. 650, 1991. 
SCHROEDER, Friedrich-Christian. Zur Strafbarkeit von Tötungen in Staatlichem Auftrag. Juristenzeitung, Tübingen, p. 990-993, 1992.

.Zehn Jahre strafrechtliche Aufarbeitung des DDR-Unrechts. Neue Juristische Wochenschrift, München, n. 41, p. 3.017-3.021, 2000.

- Geschichtsbewältigung durch Strafrecht? In: HOYER, Andreas. Beiträge zur gesetzgebungslehre und zur strafrechts dogmatik. Heidelberg: Müller, 2001. p. 62-84.

. Möglichkeiten und Formen der Bewältigung staatskrimineller Vergangenheit. In: RILL, Bernd. Vergangenheitsbewältigung im Osten: Russland, Polen, Rumänien. München: Hanns-SeidelStiftung, 2008. p. 9-16.

VORMBAUM, Thomas. Einführung in die moderne Strafrechtsgeschichte. Heidelberg: Spring, 2009.

WEBER, Hermann. Die DDR: 1945-1990. Munich: Oldenbourg Wissenschaftsverlag, 1999. 